\title{
Heat of Combustion of Coffee Pulp and Husks as Alternative Sources of Renewable Energy
}

\author{
Hannington Twinomuhwezi, Pius Wozeyi, Victory S. Igwe, \\ Ikechukwu O. Amagwula, and Chinaza G. Awuchi
}

\section{ABSTRACT}

\begin{abstract}
The study determined the amount of heat energy (heat of combustion) produced per unit mass from coffee pulp and coffee husks to see if these can be used as alternative sources of energy. The samples were obtained from Mount Elgon areas in Eastern Uganda. The objectives determined the amount of heat produced per unit mass from coffee husk and pulp and compared the amount of heat produced per unit mass from the coffee husk and coffee pulp. The coffee husk and pulp were dried, ground and sieved using a 150 microns diameter sieve. The resultant powder was analyzed using IKA C200 bomb calorimeter. The Heat values produced per unit mass from coffee husk and pulp were $15.389 \mathrm{KJg}^{-1}$ and $13.755 \mathrm{KJg}^{-1}$ respectively. Further analysis showed that both coffee pulp and coffee husks could be used as fuels for renewable energy. However, from the findings, it is recommended that coffee husks should be preferred as a better source of fuel since it generated $1.634 \mathrm{KJg}^{-1}$ more energy than the coffee pulp. Comprehensive study should be carried out on the two samples to obtain a complete fuel description of the samples.
\end{abstract}

Keywords: Calorific value (heat of combustion), Coffee husks, Coffee pulp, Renewable energy.

\author{
Submitted : February 8, 2021 \\ Published : March 4, 2021 \\ ISSN: $2684-1827$ \\ DOI: 10.24018 /ejfood.2021.3.2.241 \\ Hannington Twinomuhwezi \\ Department of Chemistry, Kyambogo \\ University, Kampala, Uganda. \\ School of Engineering and Applied \\ Sciences, Kampala International \\ University, Kampala, Uganda. \\ (e-mail: thannington@yahoo.com) \\ Pius Wozeyi \\ Department of Chemistry, Kyambogo \\ University, Kampala, Uganda. \\ (e-mail: piuswozeyi@gmail.com) \\ Victory S. Igwe \\ Department of Food Science and \\ Technology, Federal University of \\ Technology Owerri, Owerri, Nigeria. \\ (e-mail: victoryigwe@gmail.com) \\ Ikechukwu O. Amagwula \\ Department of Food Science and \\ Technology, Federal University of \\ Technology Owerri, Owerri, Nigeria. \\ (e-mail: ikechukwuamagwula@gmail.com) \\ Chinaza G. Awuchi* \\ School of Engineering and Applied \\ Sciences, Kampala International \\ University, Kampala, Uganda. \\ (e-mail: awuchichinaza@gmail.com)
}

*Corresponding Author

\section{INTRODUCTION}

Many countries use agricultural biomass to make up for most of their energy requirements, although, the efficiencies may be low, and thus the raw material usage is low [1]. Woody biomass can be used as wood energy to provide at least $93 \%$ of a country's energy needs [2]. During coffee processing, substantial bulk of coffee husk and pulp are generated. A research reported that, in total, coffee husks and pulp of 46.6 MT were recovered from 233 MT of coffee manufactured, based on 0.2 waste factor for coffee [3]. These coffee husks and pulp are used as beddings in some poultry units. This study therefore intended to determine the heat of combustion produced per unit mass from the coffee pulp and husks to enable further traditional and modern coffee waste conversions to be undertaken in all forms.

Rural populations and some urban populations in developing countries such as Uganda heavily rely on wood fuel for heating purposes. This has led to deforestation and environmental degradation which result into changes in the climate patterns. However, there are alternative materials which can provide fuel which is environmentally friendly like coffee husks and coffee pulp which are not widely utilized, and if these materials are utilized, such environmental challenges will be addressed. Therefore, this study is done to determine the amount of heat value produced per unit mass from coffee husks and coffee pulp to mitigate these challenges.

The objective of the study aimed at determining the heat of combustion per unit mass produced by coffee husks and coffee pulp with a view of using them as alternative sources of renewable fuel (energy). The overdependence on wood fuel in most of the traditional communities is a major cause of deforestation. This has brought about climate change and accumulation of greenhouse gases. Hence development of technologies for utilization of coffee husks and coffee pulp is vital to minimize the above challenge. Improper disposal of 
agricultural residues and other organic wastes has got a number of environmental impacts. One of the major environmental effects is that when organic materials are left in the bulk in open air for considerable times, they are fermented by anaerobic bacteria in the presence of moisture to emit methane which has about 21 times as much greenhouse effect as carbon dioxide. Thus, utilizing these materials as sources of energy for domestic and industrial use can help in mitigating the above environmental concern.

The dependence on fossil fuels for heating purposes is associated with several problems including supply insecurity, variable and ever rising prices and greenhouse gases (GHGs) emission. Therefore, utilizing coffee husks and coffee pulp for domestic and industrial fuel in coffee producing areas, if found feasible, will reduce dependence on fossil fuels and provide clean, cheap, sustainable, and reliable energy supply for the area. Boosting the economic status and improving on the standards of living of the surrounding communities involved in coffee growing. Once the development of technologies for utilization of coffee pulp and coffee husks has been established, the surrounding communities will sell these residues to the briquette making industry hence increasing their income and improving on the standard of living.

\section{Methods AND MATERIALS}

\section{A. Research Design}

The research was both field and laboratory based. The field based involved the collection of samples of coffee pulp and coffee pulp. These materials were collected from the slopes of Mount Elgon. This is because most people around the area grow coffee on a large scale, especially Arabic coffee. The laboratory based involved the use of the bomb calorimeter to determine the heat value of these fuels. The experimental setup involved measuring instruments like the digital beam balance and the bomb calorimeter.

\section{B. Material Collection}

The coffee pulp was obtained from Gibuzale Kyakalanyi coffee washing station in Suguta parish, Bumugibole subcounty, Bulambuli district, Eastern Uganda. Coffee husks were obtained from Kawacom Mbale coffee milling plant Located in Mbale town, industrial area where dry coffee beans are processed.

\section{Sample Preparation}

The coffee husks were collected and dried under the sun for two days to approximately $12 \%$ moisture content and then taken to the maize huller and crushed thoroughly to obtain fine particle sizes. This was then sieved in the sieve of 150 microns (100 BSS) diameter to obtain a fine powder for analysis. The coffee pulp was collected and dried under the sun for three days to reduce the moisture content as low as possible to approximately $13 \%$. The dry pulp was then taken to the maize huller and crushed to obtain fine particle sizes. This powder was then sieved in a sieve of 150 microns (100BSS) diameter to obtain a fine powder for analysis and avoid variations in the results which could be due to difference in particle sizes. This was then ready for proximate analysis.

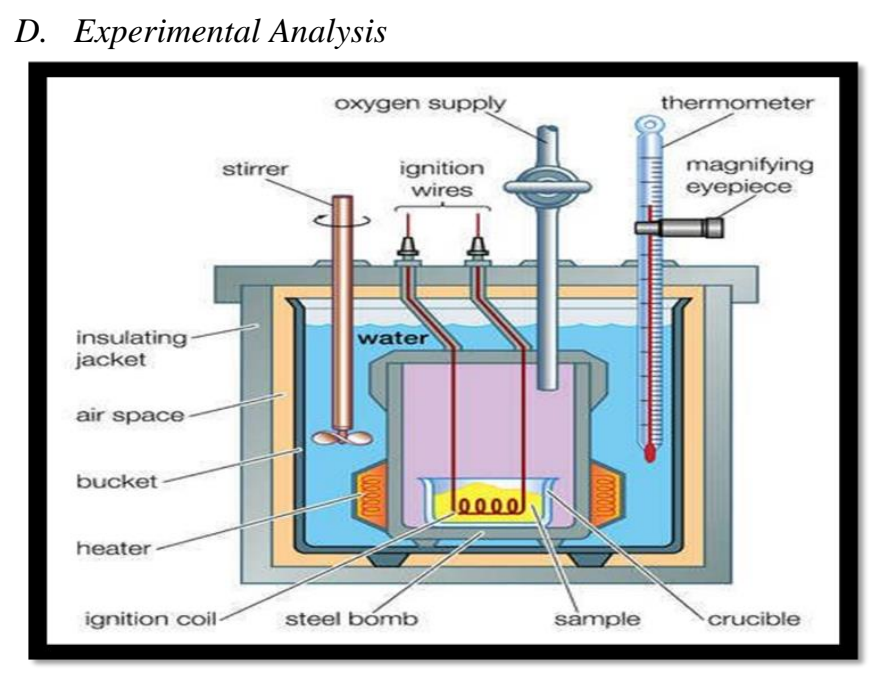

Fig. 1. Internal structure of the bomb calorimeter.

The apparatus of the experiment was arranged as shown in the Figure 1. A 0.2 gram of the fuel under investigation was weighed using the digital beam balance and its value recorded. A pellet with a cotton thread passing through it was made by use of the pellet making machine of the bomb calorimeter. The bomb calorimeter was calibrated using C723 benzoic acid of known heat of combustion and a standard reference value was obtained and recorded. The pellet made of the solid fuel under investigation was tied on the filament of the bomb with the help of the cotton thread whose heat correction is known i.e., 50J. The pellet was attached in such a way that it is directly above the crucible of the bomb. The lid of the bomb was screwed tightly, and the bomb filled with oxygen up to around 35-40 atmospheres of pressure. The bomb was then carefully inserted between the three electrodes of the instrument and the vessel closed successfully. The water bucket of the bomb calorimeter was filled with water up to the required volume. At this point, the calorimeter was switched on from the electric mains. The initial temperature was read and recorded, and other temperatures were recorded after one-minute intervals. The calorimeter performs the main test and calculates the value of the heat of combustion (HHV) per unit mass (gram) which was displayed on the screen. The value was read and recorded. After the calorimeter completes the test, the water was drained from the bucket by opening the vessel. The bomb was removed, and the oxygen driven out. It was then opened, and the inner surface was cleaned of any ash. The experiment was repeated over three times under same conditions to ensure reliability and validity of results. The procedure was repeated to obtain results of other samples of the solid fuel under investigation.

\section{RESULTS AND DISCUSSION}

\section{A. Introduction}

The data collected from the study and heat value determined per unit mass of coffee pulp and coffee husks by experimental study are presented and discussed. 


\section{B. Heat of Combustion (Calorific value)}

The results of the heat of combustion per unit mass for both the coffee pulp and coffee husks are presented as in this section.

\section{Heat of combustion per unit mass of coffee husks}

A 0.2 gram of the coffee husk was analyzed using the bomb calorimeter and the results for the findings were recorded in the Table 1 and 2.

TABLE 1: TEMPERATURE CHANGE PER UNIT TIME OF COFFEe HuSKS

\begin{tabular}{|c|c|c|c|c|c|c|c|}
\hline \multirow{2}{*}{$\begin{array}{c}\text { Time } \\
\text { (minutes) }\end{array}$} & \multicolumn{2}{|c|}{ TEST 1} & \multicolumn{2}{|c|}{ TEST 2} & \multicolumn{2}{|c|}{ TEST 3} & \multirow[t]{2}{*}{$\begin{array}{c}\Delta \\
(\mathrm{KK}) \\
\end{array}$} \\
\hline & $\begin{array}{c}\mathrm{T}_{1} \\
(\mathrm{KK}) \\
\end{array}$ & $\begin{array}{c}\Delta_{1} \\
(\mathrm{KK})\end{array}$ & $\begin{array}{c}\mathrm{T}_{2} \\
(\mathrm{KK}) \\
\end{array}$ & $\Delta_{2}(\mathrm{KK})$ & $\begin{array}{c}\mathrm{T}_{3} \\
(\mathrm{KK}) \\
\end{array}$ & $\begin{array}{c}\Delta_{3} \\
(\mathrm{KK}) \\
\end{array}$ & \\
\hline 1 & 0.0179 & 0.0000 & 0.0446 & 0.0000 & 0.0414 & 0.0000 & 0.0000 \\
\hline 2 & 0.0246 & 0.0067 & 0.0612 & 0.0166 & 0.0567 & 0.0153 & 0.0129 \\
\hline 3 & 0.0286 & 0.0040 & 0.0668 & 0.0056 & 0.0621 & 0.0054 & 0.0051 \\
\hline 4 & 0.0323 & 0.0037 & 0.0704 & 0.0036 & 0.0659 & 0.0038 & 0.0037 \\
\hline 5 & 0.0355 & 0.0032 & 0.0735 & 0.0031 & 0.0693 & 0.0034 & 0.0032 \\
\hline 6 & 0.2369 & 0.2014 & 0.2749 & 0.2014 & 0.2731 & 0.2038 & 0.2022 \\
\hline 7 & 0.3492 & 0.1123 & 0.3862 & 0.1113 & 0.3794 & 0.1063 & 0.1099 \\
\hline 8 & 0.3755 & 0.0263 & 0.4101 & 0.0239 & 0.4051 & 0.0257 & 0.0253 \\
\hline 9 & 0.3872 & 0.0117 & 0.4212 & 0.0111 & 0.4165 & 0.0114 & 0.0114 \\
\hline 10 & 0.3942 & 0.0070 & 0.4271 & 0.0059 & 0.4226 & 0.0061 & 0.0063 \\
\hline 11 & 0.3989 & 0.0047 & 0.4310 & 0.0039 & 0.4270 & 0.0044 & 0.0043 \\
\hline 12 & 0.4026 & 0.0037 & 0.4339 & 0.0029 & 0.4306 & 0.0036 & 0.0034 \\
\hline 13 & 0.4060 & 0.0034 & 0.4366 & 0.0027 & 0.4333 & 0.0027 & 0.0029 \\
\hline
\end{tabular}

TABLE 2: HeAT VALUE ANALYSIS OF COFFEE HUSK

\begin{tabular}{cccc}
\hline $\mathrm{M}_{\mathrm{f}}(\mathrm{g})$ & $\mathrm{T}_{1}(\mathrm{KK})$ & $\mathrm{T}_{2}(\mathrm{KK})$ & $\mathrm{HHV}(\mathrm{J} / \mathrm{g})$ \\
\hline 0.2081 & 0.0179 & 0.4060 & 15331 \\
0.2034 & 0.0446 & 0.4366 & 15475 \\
0.2037 & 0.0414 & 0.4333 & 15363 \\
\hline
\end{tabular}

$\mathrm{M}_{\mathrm{f}}=$ mass of the fuel analyzed; Energy equivalent of the bomb (IKA C200) $=23621 \mathrm{~J} / \mathrm{g} ; \mathrm{T}_{1}=$ Initial temperature reading; $\mathrm{T}_{2}=$ Final temperature reading.

The average HHV per gram of coffee husks = $\frac{15331+15475+15363}{3}=15389.667 \mathrm{Jg}^{-1}=15.389 \mathrm{KJg}^{-1}$

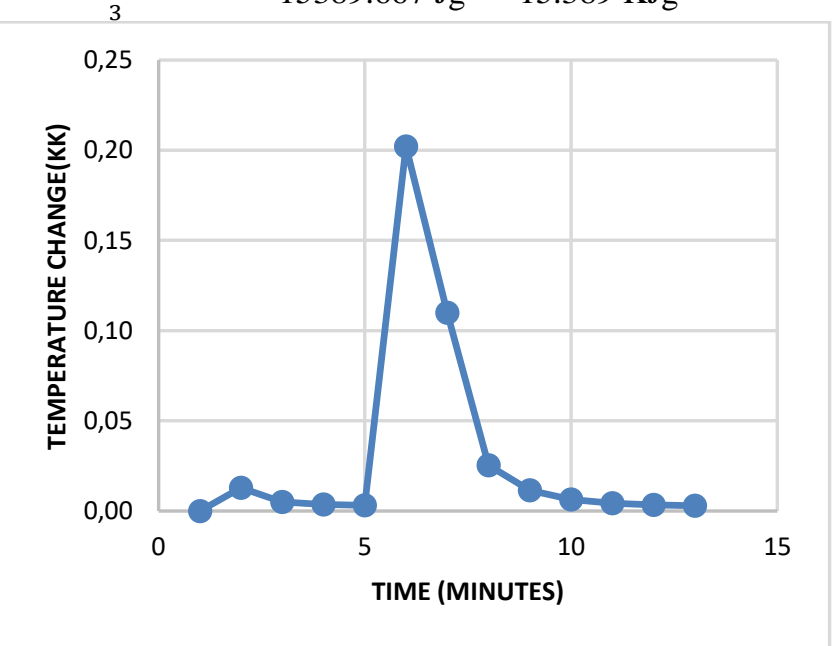

Fig. 2. Temperature change against time for coffee husks.

The average amount of heat energy produced per unit mass by coffee husks according in this study was $15.389 \mathrm{KJg}^{-1}$ with a maximum temperature of $425.3 \mathrm{~K}$ and a maximum temperature change of $200 \mathrm{~K}$. The value obtained is related the value of $5041.1 \mathrm{cal} / \mathrm{g}$ reported by Weldemedhin et al. [6] for calorific value of briquettes made from coffee husk. This energy value produced by the coffee husk fuel is high and is half that of charcoal which is widely used for heating purposes with a heat value $30.531 \mathrm{KJ} / \mathrm{g}$. Therefore, this suggests that the coffee husk fuel has a high energy density stored per unit mass hence the volatile matter and fixed carbon content that constitutes the combustible part of the fuel in the coffee husk fuel is greater than the Noncombustible part (moisture content and the ash content). Energy in food crops is mainly generated from carbohydrates, fats, and proteins [4], [5].

From the graph, there is a gradually stiff change of temperature in the $1^{\text {st }}$ minute showing a faster response of water to the heat produced from the fuel (coffee husks) and also from the ignition of the cotton attached to the filament of the bomb. This suggests that the fuel ignites well when being set on fire which gives a good characteristic of the fuel. However, after the $1^{\text {st }}$ minute, there is gradual decrease in the temperature between the $2^{\text {nd }}$ and the $5^{\text {th }}$ minute. This gradual decrease is due to the fuel igniting. However, after the $5^{\text {th }}$ minute, there is a rapid increase in the temperature change of the water up to the $6^{\text {th }}$ minute. This shows the burning period of the fuel. Beyond this time, the rate of temperature change of the water decreased drastically between the $6^{\text {th }}$ and the $8^{\text {th }}$ minute. This indicates complete combustion of the coffee husks (fuel). However, beyond the $8^{\text {th }}$ minute there was a gradual decrease in the temperature change of the water and almost remains constant. This was also due to complete combustion of the fuel and there nothing is left burning to produce more heat than the non-combustible component of the fuel.

\section{Heat value (heat of combustion) per unit mass of coffee pulp}

A $0.2 \mathrm{~g}$ of the coffee pulp was analyzed using the bomb calorimeter and the results for the findings were recorded in the table as shown below.

TABLE 3: Temperature Change Per Unit MASS OF COFFEe PulP

\begin{tabular}{|c|c|c|c|c|c|c|c|}
\hline \multirow{2}{*}{$\begin{array}{c}\text { Time } \\
\text { (minutes) }\end{array}$} & \multicolumn{2}{|c|}{ TEST 1} & \multicolumn{2}{|c|}{ TEST 2} & \multicolumn{2}{|c|}{ TEST 3} & \multirow{2}{*}{$\begin{array}{c}\Delta \\
(\mathrm{KK})\end{array}$} \\
\hline & $\begin{array}{c}\mathrm{T}_{1} \\
(\mathrm{KK})\end{array}$ & $\begin{array}{c}\Delta_{1} \\
(\mathrm{KK})\end{array}$ & $\begin{array}{c}\mathrm{T}_{2} \\
(\mathrm{KK})\end{array}$ & $\begin{array}{c}\Delta_{2} \\
(\mathrm{KK})\end{array}$ & $\begin{array}{c}\mathrm{T}_{3} \\
(\mathrm{KK})\end{array}$ & $\begin{array}{c}\Delta_{3} \\
(\mathrm{KK})\end{array}$ & \\
\hline 1 & 0.0481 & 0.0000 & 0.0308 & 0.0000 & 0.0274 & 0.0000 & 0.0000 \\
\hline 2 & 0.0489 & 0.0008 & 0.0442 & 0.0134 & 0.0435 & 0.0161 & 0.0101 \\
\hline 3 & 0.0537 & 0.0048 & 0.0494 & 0.0052 & 0.0489 & 0.0054 & 0.0052 \\
\hline 4 & 0.0578 & 0.0041 & 0.0532 & 0.0038 & 0.0531 & 0.0042 & 0.0040 \\
\hline 5 & 0.0615 & 0.0037 & 0.0567 & 0.0035 & 0.0563 & 0.0032 & 0.0035 \\
\hline 6 & 0.2306 & 0.1691 & 0.2308 & 0.1741 & 0.2445 & 0.1882 & 0.1771 \\
\hline 7 & 0.3235 & 0.0929 & 0.3309 & 0.1001 & 0.3493 & 0.1048 & 0.0993 \\
\hline 8 & 0.3468 & 0.0233 & 0.3540 & 0.0231 & 0.3732 & 0.0239 & 0.0234 \\
\hline 9 & 0.3580 & 0.0112 & 0.3656 & 0.0116 & 0.3846 & 0.0114 & 0.0114 \\
\hline 10 & 0.3645 & 0.0065 & 0.3720 & 0.0064 & 0.3910 & 0.0064 & 0.0064 \\
\hline 11 & 0.3692 & 0.0047 & 0.3768 & 0.0048 & 0.3957 & 0.0047 & 0.0047 \\
\hline 12 & 0.3727 & 0.0035 & 0.3807 & 0.0039 & 0.3994 & 0.0037 & 0.0037 \\
\hline 13 & 0.3761 & 0.0034 & 0.3843 & 0.0036 & 0.4027 & 0.0033 & 0.0034 \\
\hline
\end{tabular}

$\mathrm{T}_{1}=$ temperature reading at different times for test $1 ; \mathrm{T}_{2}=$ temperature reading at different times for test $2 ; \mathrm{T}_{3}=$ temperature reading at different times for test $3 ; \Delta=$ average temperature change for coffee pulp.

\begin{tabular}{cccc}
\multicolumn{4}{c}{ TABLE 4: HeAt Value AnAlysis OF COFFEE PUlP } \\
\hline $\mathrm{M}_{\mathrm{f}}(\mathrm{g})$ & $\mathrm{T}_{1}(\mathrm{KK})$ & $\mathrm{T}_{2}(\mathrm{KK})$ & $\mathrm{HHV}(\mathrm{J} / \mathrm{g})$ \\
0.2010 & 0.0481 & 0.3761 & 13100 \\
0.2023 & 0.0308 & 0.3843 & 13763 \\
0.2041 & 0.0274 & 0.4027 & 14402 \\
\hline
\end{tabular}

$\mathrm{M}_{\mathrm{f}}=$ mass of the fuel analyzed; Energy equivalent of the bomb (IKA C200) $=23621 \mathrm{~J} / \mathrm{g} ; \mathrm{T}_{1}=$ Initial temperature reading; $\mathrm{T}_{2}=$ Final temperature reading.

The average HHV per gram of coffee pulp = $\frac{13100+13763+14402}{3}=13755 \mathrm{Jg}^{-1}=13.755 \mathrm{KJg}^{-1}$ 


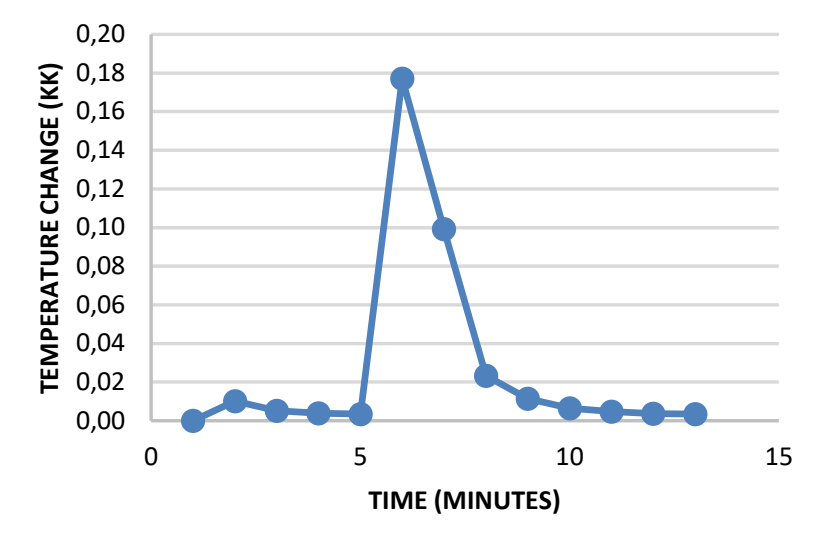

Fig. 3. Temperature change against time for coffee pulp.

The average amount of heat energy produced per unit mass by coffee pulp according to this study was $13.755 \mathrm{KJg}^{-1}$ with a maximum temperature of $387.7 \mathrm{~K}$ and a maximum temperature change of $180 \mathrm{~K}$. The value obtained is related the value of $4037.6 \mathrm{cal} / \mathrm{g}$ reported by Weldemedhin et al. [6] for calorific value of briquettes made from coffee pulp. The energy value produced by the coffee pulp fuel is low as compared to that of coffee husk and is also approximately half the heat value of charcoal. This low value of the energy content suggests that the coffee pulp fuel has a low energy density stored per unit mass of the coffee pulp therefore the volatile matter and fixed carbon content that constitutes the combustible part of the fuel is less than the Non-combustible part (moisture and ash content) [4], [6]. Therefore, it implies that coffee pulp fuel has a low energy content value because of the high composition of moisture content and ash content.

From the graph, there was gradual change of temperature between the $1^{\text {st }}$ and the $5^{\text {th }}$ minute showing a slow response of water to the heat produced from the fuel. This suggests that the fuel ignites poorly when being set on fire, which gives poor characteristics of the fuel. However, after the $5^{\text {th }}$ minute, there is a steep increase in the temperature change of the water up to the $6^{\text {th }}$ minute. This suggests the burning period of the fuel. Beyond this time, there is a steep decrease in the temperature of the water in between the $6^{\text {th }}$ and the $8^{\text {th }}$ minute. This indicates complete combustion of the fuel. Beyond the $8^{\text {th }}$ minute there is a gradual decrease in the temperature change of the water and almost remains constant by the $13^{\text {th }}$ minute. This suggests the heat being produced by the noncombustible component of the fuel (ash and minerals) after the combustion of the fuel.

\section{Comparison of Heat Value Produced per Unit Mass from Coffee Husk and Pulp}

The average amount of Heat values produced from coffee husks and coffee pulp according to this study were 15.389 $\mathrm{KJg}^{-1}$ and $13.755 \mathrm{KJg}^{-1}$ respectively. These values agree with the values of 5041.1 and $4037.6 \mathrm{cal} / \mathrm{g}$ reported by Weldemedhin et al. [6] for briquettes made from coffee husks and pulp, respectively. From the results of this study, it was observed that the energy content produced by the coffee husks was 1.119 times that produced by the coffee pulp. From the graphs of temperature change of the two fuels, it was observed that the maximum temperature produced by coffee husk and coffee pulp fuel is $425.3 \mathrm{~K}$ and $387.7 \mathrm{~K}$ respectively. This therefore implies that the maximum temperature produced by coffee husks is 1.097 times that produced by the coffee pulp. From the same graphs of the two fuels, it was also observed that the maximum temperature change produced by the coffee husk fuel is higher than of the coffee pulp fuel and also the ignition temperature of the coffee husk was low compared to that of the coffee pulp.

\section{CONCLUSION}

The coffee husks and coffee pulp obtained after coffee processing were critically analyzed to meet the objectives of the study. From the study findings, it has been revealed that the energy content of the coffee husk fuel and coffee pulp fuel is $15.389 \mathrm{KJg}^{-1}$ and $13.755 \mathrm{KJg}^{-1}$ respectively. It can be concluded that coffee husk and pulp have high potential as a source of renewable and environmentally friendly energy, which reduces pollution as well as provide a sound coffee waste management option. However, it should be noted the energy content of coffee husk is greater than that of coffee pulp but by a small magnitude. Therefore, the coffee husk take priority as an alternative source of environmentally friendly energy.

\section{ACKNOWLEDGEMENT}

The authors are grateful the Lab Technicians of Chemistry Department, Kyambogo University, and those who assisted in this study in one way or the other.

\section{CONFLICT OF INTEREST}

The authors declare no conflict of interest whatsoever.

\section{REFERENCES}

[1] Zanchi, G., Frieden, D. and Pucker, J. Climate benefits from alternative energy uses of biomass plantations in Uganda. Biomass Bioenergy, 2013, 1(59), 128-136.

[2] Bingh Lars Petter: Opportunities for utilizing waste biomass for energy in Uganda. Master's Thesis, Department of Energy and process Engineering, Kyambogo University, Uganda. 2004.

[3] Abbasi, T. and Abbasi, S. A. Biomass energy and the environmental impacts associated with its production and utilization, Renewable Sustainable Energy Review, 2010, 3(14), 919-937.

[4] Hannington T, Awuchi, CG, and Mihigo R. "Comparative Study of the Proximate Composition and Functional Properties of Composite Flours of Amaranth, Rice, Millet, and Soybean". American Journal of Food Science and Nutrition, 2020, 6 (1): 6-19.

[5] Awuchi, CG. "Proximate Composition and Functional Properties of Different Grain Flour Composites for Industrial Applications”. Inter'l J Food Sci, 2019, 2 (1): 43 - 64.

[6] Weldemedhin M, Alemayehu H, Esayas A, and Argaw A. "The Potential of Coffee Husk and Pulp as an Alternative Source of Environmentally Friendly Energy". East African Journal of Sciences, 2014, 8(1) 29-36. 